\title{
Fine-Needle Aspiration Biopsy of Palpable Breast Masses: Patterns of Clinical Use and Patient Experience
}

\author{
Amy Ly, MD ${ }^{a, *} ;$ Jill C. Ono, MD ${ }^{b, *} ;$ Kevin S. Hughes, MD; ${ }^{c}$ Martha B. Pitman, MD ${ }^{a}$; and \\ Ronald Balassanian, $\mathrm{MD}^{\mathrm{d}, *}$
}

\begin{abstract}
Background: Timeliness is an important and recognized measure of health care quality. Multiple health organizations worldwide have published timeliness targets for breast cancer care. We performed the first comparison of patient wait times and utilization patterns for palpable breast mass diagnosis and treatment with regard to biopsy method. Patients and Methods: Palpable breast masses in women biopsied via a fine-needle aspiration (FNA) or core biopsy at 2 affiliated academic medical centers in 2009 were analyzed if subsequently treated with excision or neoadjuvant therapy. Patient demographics, mass size and radiologic features, pathology diagnoses, and wait times to diagnosis and treatment were recorded. Results: Patients diagnosed by FNA biopsy received their biopsy diagnosis more than 8 days sooner than those diagnosed by core biopsy. Most FNA biopsies occurred the same day the patient clinically presented. Time to treatment did not differ significantly between groups. Both biopsy methods demonstrated comparable diagnostic accuracy. Breast masses diagnosed by FNA biopsy had Breast Imaging Reporting and Data System (BI-RADS) scores ranging from 1 through 5, whereas nearly all core biopsy cases had a BI-RADS score of 4 or greater. All patient groups were demographically comparable and presented with similar breast mass sizes. Conclusions: Wait times for breast biopsies were significantly shorter for patients diagnosed by FNA compared with core biopsy. FNA biopsy was often used to evaluate breast masses of low clinical suspicion. In light of health care goals for practice improvement and cost containment, breast FNA biopsy may be an underused resource.
\end{abstract}

J Natl Compr Canc Netw 2016;14(5):527-536

\section{Background}

The American Cancer Society estimated that 232,670 new cases of female breast cancer would occur in 2014, with more than 1 million women undergoing breast biopsy. ${ }^{1,2}$ The prediagnosis period in particular is a time of acute distress regardless of the ultimate pathology diagnosis, and it begins the moment a woman is told she needs a breast biopsy. ${ }^{3-5}$ In one study, waiting for a breast biopsy was quantifiably more anxiety-inducing than waiting for an invasive therapeutic procedure for known malignancy. ${ }^{6}$ There is yet additional patient stress when waiting periods between health care visits are considered by the patient to be unreasonably long. ${ }^{5}$ Longer waits for breast biopsy may also contribute to

From a Massachusetts General Hospital, Pathology Service, Boston, Massachusetts; 'Laboratory Medicine Consultants, LTD, Las Vegas, Nevada; 'Massachusetts General Hospital, Department of Surgery, Boston, Massachusetts; and dUniversity of California, San Francisco, Department of Pathology, San Francisco, California.

*Work partly performed at Brigham and Women's Hospital, Pathology Service, Boston, Massachusetts. patient perception of diagnostic delay in both primary and recurrent/metastatic disease settings, particularly if the patient is the first to detect the abnormality. ${ }^{7}$ It was not surprising, therefore, that reducing diagnostic wait times down to several hours at "one-stop" breast care clinics offering same-day fine-needle aspiration biopsy (FNAB) diagnosis produced extraordinary emotional relief for patients. ${ }^{4}$ In addition to significant psychological distress, health care delays may cause increased morbidity from more extensive treatment and shortened survival in some patient groups, because timely diagnosis and treatment of breast cancer are accepted as important prognostic factors. ${ }^{3,5,7-15}$

Recognizing the negative impacts of delayed medical attention, multiple European and North American health
Submitted June 19, 2015; accepted for publication January 29, 2016. The authors have disclosed that they have no financial interests, arrangements, affiliations, or commercial interests with the manufacturers of any products discussed in this article or their competitors.

Correspondence: Amy Ly, MD, Massachusetts General Hospital, Pathology Service, Warren 105, 55 Fruit Street, Boston, MA 02114.

E-mail: aly1@partners.org 
Ly et al

organizations have published timeliness targets in breast cancer-related care, despite a lack of consensus on the definition of delay. ${ }^{16-19}$ To meet these timeliness goals, providers have tried modifying referral and triage algorithms, and implementing navigation systems for patients undergoing breast evaluation. Although such endeavors have reported cost-savings, success in reducing diagnostic wait times experienced by patients has been inconsistent. ${ }^{20-24}$

We hypothesized that FNAB is able to provide patients their breast biopsy diagnoses in a more timely fashion than core biopsy, without compromising diagnostic accuracy. Although the American College of Surgeons and National Accreditation Program for Breast Centers considers both FNAB and core biopsy acceptable for diagnosing breast lesions, core biopsy is currently the preferred modality in the United States and other countries. ${ }^{25}$ The advantages and limitations of each technique have been investigated extensively in the literature. However, to our knowledge, this is the first study to compare breast biopsy methods with regard to timeliness of breast cancer-related care experienced by patients, and clinical utilization patterns by physicians.

\section{Patients and Methods}

Institutional Review Board approval was obtained from Massachusetts General Hospital (MGH) and Brigham and Women's Hospital (BWH). These 2 affiliated tertiary care academic hospitals are located less than 4 miles apart in Boston, Massachusetts, and serve similar patient populations. Each independently operates a breast cancer care center with its own clinical practice patterns. Medical chart review and search of the pathology records identified women with palpable breast masses diagnosed using either image-guided core biopsy by radiologists or palpationguided FNAB by pathologists in 2009. All FNABs in this study were performed by cytopathologists trained and experienced in palpation-guided FNAB techniques. Rapid on-site evaluation of the FNAB sample was routinely performed to ensure specimen adequacy. Cases were entered into the study if the masses were treated neoadjuvantly and/ or were subsequently excised, and all breast massrelated care occurred at a single hospital. Patient demographics, breast mass size (largest dimension by imaging, or by physical examination if radiologic size unavailable), Breast Imaging Reporting and Data System (BI-RADS) category, date of clinical presentation (date mass first detected by physical examination or screening mammogram), biopsy and surgery dates, pathology report dates and diagnoses, and neoadjuvant initiation dates were recorded.

FNAB cytology diagnoses used the $1996 \mathrm{NIH}$ uniform approach categories: nondiagnostic, negative for malignancy, atypical or suspicious for malignancy (indeterminate), and malignant. ${ }^{26}$ For comparison of diagnostic accuracy, histologic diagnoses were also assigned to benign, indeterminate, or malignant categories. Statistical analysis used Microsoft Excel 2007 single factor ANOVA and $t$ tests. Statistical significance was defined as a $P$ value less than 0.05 .

\section{Results}

\section{Patient Characteristics}

At $\mathrm{MGH}$, pathologists sampled 254 palpable breast lesions using FNABs; 50 were included in the study ("MGH-FNAB" cases). Radiologists core biopsied 937 lesions, of which 121 were entered into the study ("MGH-CB" cases). At BWH, only 3 pathologist-performed breast FNABs occurred; this patient group was not analyzed further because of low numbers. There were 1,346 breast core biopsies, 95 of which met study inclusion criteria ("BWH-CB" cases).

The constituent patients in the 3 groups were demographically similar (Table 1). Breast masses were similar in size overall, including average malignant tumor sizes in excision specimens: MGH-FNAB, $2.4 \mathrm{~cm}$; MGH-CB, $2.3 \mathrm{~cm}$; and BWH-CB, $2.1 \mathrm{~cm}$ $(P=.67)$. However, radiologically, MGH-FNAB cases ranged from BI-RADS 1 through 5, whereas $\mathrm{MGH}-\mathrm{CB}$ and BWH-CB cases were predominantly BI-RADS 4 and 5 (Table 2). The difference in BIRADS distribution between the MGH-FNAB and the 2 core biopsy groups was statistically significant $(P<.00001)$. Patient breast masses were first detected by imaging in 14 of 50 (28\%) MGH-FNAB cases, 42 of 121 (35\%) MGH-CB cases, and 7 of 95 (7.4\%) BWH-CB cases. Of the malignant tumors, 5 of $24(20.1 \%)$ MGH-FNAB cases, 33 of 84 (39.3\%) MGH-CB cases, and 6 of 72 (8.3\%) BWH-CB cases were found by screening mammogram.

\section{Diagnostic Accuracy}

Core biopsy and excision specimens showed a wide range of histologic findings. Benign 
Breast Fine-Needle Aspiration Wait Times

\begin{tabular}{|c|c|c|c|c|c|c|c|}
\hline & $\begin{array}{l}\text { Mean Patient } \\
\text { Age, y } \\
\text { (median, range) }\end{array}$ & Race & n (\%) & Education Level & n (\%) & Cancer History & $\mathbf{n}$ \\
\hline $\begin{array}{l}\text { MGH-FNAB } \\
(n=50)\end{array}$ & $\begin{array}{l}52.2 \\
(48.5,19-92)\end{array}$ & $\begin{array}{l}\text { White } \\
\text { Black } \\
\text { Hispanic } \\
\text { Asian }\end{array}$ & $\begin{array}{c}44(88 \%) \\
2(4 \%) \\
2(4 \%) \\
2(4 \%)\end{array}$ & $\begin{array}{l}\text { JHS } \\
\text { HS } \\
\text { College or higher }\end{array}$ & $\begin{array}{c}3(6 \%) \\
14(28 \%) \\
33(66 \%)\end{array}$ & $\begin{array}{l}\text { DCIS/IBC } \\
\text { IBC and nonbreast } \\
\text { carcinoma } \\
\text { Lymphoma } \\
\text { Phyllodes tumor } \\
\text { BRCA1 mutation }\end{array}$ & $\begin{array}{r}18 \\
1 \\
\\
1 \\
1 \\
1\end{array}$ \\
\hline $\begin{array}{l}\text { MGH-CB } \\
(n=120)\end{array}$ & $\begin{array}{l}54.2 \\
(53,20-91)\end{array}$ & $\begin{array}{l}\text { White } \\
\text { Black } \\
\text { Hispanic } \\
\text { Asian } \\
\text { Unknown }\end{array}$ & $\begin{array}{c}89(74 \%) \\
9(7.5 \%) \\
9(7.5 \%) \\
4(3.3 \%) \\
9(7.5 \%)\end{array}$ & $\begin{array}{l}\text { None } \\
\text { JHS } \\
\text { HS } \\
\text { College or higher } \\
\text { Unknown }\end{array}$ & $\begin{array}{c}1(0.8 \%) \\
7(5.8 \%) \\
16(13.3 \%) \\
61(50.8 \%) \\
35(29 \%)\end{array}$ & $\begin{array}{l}\text { DCIS/IBC } \\
\text { Nonbreast carcinoma } \\
\text { Melanoma } \\
\text { Lymphoma } \\
\text { Skin malignancy } \\
\text { ALH/LCIS } \\
\text { IBC and nonbreast } \\
\text { carcinoma } \\
\text { Renal Wilms tumor } \\
\text { Phyllodes tumor }\end{array}$ & $\begin{array}{r}10 \\
4 \\
3 \\
2 \\
2 \\
2 \\
1 \\
\\
1 \\
1\end{array}$ \\
\hline $\begin{array}{l}\text { BWH-CB } \\
(n=92)\end{array}$ & $\begin{array}{l}52.6 \\
(51,18-86)\end{array}$ & $\begin{array}{l}\text { White } \\
\text { Black } \\
\text { Hispanic } \\
\text { Asian } \\
\text { Unknown }\end{array}$ & $\begin{array}{c}72(78.3 \%) \\
8(8.7 \%) \\
5(5.4 \%) \\
5(5.4 \%) \\
2(2.2 \%)\end{array}$ & $\begin{array}{l}\text { JHS } \\
\text { HS } \\
\text { College } \\
\text { Unknown }\end{array}$ & $\begin{array}{c}1(1.1 \%) \\
27(29.3 \%) \\
55(59.8 \%) \\
9(9.8 \%)\end{array}$ & $\begin{array}{l}\text { IBC } \\
\text { IBC and lymphoma } \\
\text { Melanoma } \\
\text { Pelvic sarcoma } \\
\text { Phyllodes tumor }\end{array}$ & $\begin{array}{l}5 \\
1 \\
1 \\
1 \\
1\end{array}$ \\
\hline
\end{tabular}

Percentages may not total 100 due to rounding.

Abbreviations: ALH/LCIS, atypical lobular hyperplasia/lobular carcinoma in situ; BWH, Brigham and Women's Hospital; CB, core biopsy; DCIS, breast ductal carcinoma in situ; FNAB, fine-needle aspiration biopsy; HS, high school; IBC, invasive breast carcinoma; JHS, junior high school; MGH, Massachusetts General Hospital.

diagnoses included fibrous tissue/scar, fibrocystic change, mastitis, keratin cyst, bacterial infection, pseudoangiomatous stromal hyperplasia, fat necrosis, lipoma, fibroadenoma, hamartoma, radial scar in an excision specimen, and papilloma. Indeterminate lesions encompassed radial scar in a core biopsy, atypical papillary lesion, flat epithelial atypia (FEA), atypical ductal hyperplasia, atypical lobular hyperplasia/lobular carcinoma in situ (ALH/LCIS), fibromatosis, unclassified fibroepithelial lesion, and nonmalignant Phyllodes tumors. Malignant cases contained ductal carcinoma in situ (DCIS) with and without associated invasive breast carcinoma (IBC).

Fifty MGH-FNAB cases were included in the study, of which 34 (68\%) were directly excised after initial biopsy. Pathology diagnosis was concordant between biopsy and excision for 24 cases, with minor discrepancies in 10 (Figure 1). Benign FNAB diagnoses in this group were excised due to concern for diagnostic discordance $(n=6)$; change in physical examination, such as enlargement, hardening, and increased prominence of the mass $(n=2)$; treatment ( 1 keratin cyst, 1 persistent infection); patient preference $(n=2)$; and cosmesis $(n=2)$. Sixteen (32\%) MGH-FNAB cases underwent a second biopsy before excision: 15 by core biopsy and 1 by FNAB (Figure 2). Benign FNAB diagnoses in this subset $(n=4)$ were rebiopsied for possible diagnostic discordance $(\mathrm{n}=2)$ and interval enlargement of the mass $(n=2)$. Concordance for benign and malignant FNAB and excision diagnoses $(n=34)$ was $91.2 \%$. United Kingdom National Health Service Breast Screening Programme (UK NHS BSP) cytology performance standards were met or exceeded by the MGH-FNAB group, except for a mildly elevated "suspicious for malignancy" rate (Table 3). ${ }^{27}$

Overall diagnostic concordance in $\mathrm{MGH}-\mathrm{CB}$ cases was $87.6 \%$, with minor diagnostic discrepancies in 17 cases. A total of 105 masses were directly excised after biopsy (Figure 3). Benign biopsy diagnoses were excised for possible nonconcordance or surgeon desire for more definitive diagnosis $(n=6)$, treatment $(n=1)$, mass enlargement $(n=1)$, and patient preference $(n=5)$. Sixteen biopsies containing IBC were treated neoadjuvantly. Postneoadjuvant excisions showed residual IBC $(n=6)$ and complete pathologic response $(n=2)$. Eight patients with widely metastatic disease did not undergo surgery on completion of neoadjuvant therapy. In 2 instances, the excision "upgraded" the core biopsy diagnosis from DCIS to IBC. UK NHS BSP analysis demon- 
Ly et al

\begin{tabular}{|lll|}
\hline Table 2. & $\begin{array}{l}\text { Breast Mass Clinical and Radiologic } \\
\text { Characteristics }\end{array}$ \\
& $\begin{array}{l}\text { Mean Breast Mass } \\
\text { Bi-RADS } \\
\text { Category }\end{array}$ & $\begin{array}{l}\text { Size, } \\
\text { (median, range) }\end{array}$ \\
\hline MGH-FNAB & 1: $7(14 \%)$ & $1.8(1.5,0.4-7.0)$ \\
$(n=50)$ & $2: 8(16 \%)$ & \\
& $4: 19(38 \%)$ & \\
& $5: 8(16 \%)$ & \\
MGH-CB & N/A: $8(16 \%)$ & \\
$(n=121)$ & 5: $88(72.7 \%)$ & \\
& N/A: $15(14.9 \%)$ & \\
BWH-CB & 3: $1(1.1 \%)$ & \\
$(n=95)$ & $4: 57(60 \%)$ & \\
& $5: 33(34.7 \%)$ & \\
& N/A: $4(4.2 \%)$ & \\
\hline
\end{tabular}

Percentages may not total 100 due to rounding.

Abbreviations: BI-RADS, Breast Imaging Reporting and Data System; BWH, Brigham and Women's Hospital; $C B$, core biopsy; FNAB, fineneedle aspiration biopsy; MGH, Massachusetts General Hospital; N/A, not available.

strated that MGH-CB was more sensitive but less specific than MGH-FNAB (Table 3).

Of the 95 BWH-CB-sampled masses, 81 were directly followed by direct excision (Figure 4). Excision of the benign core biopsy diagnoses was prompted by concern for radiologic-pathologic discordance $(n=5)$, patient preference $(n=4)$, and treatment of infection $(\mathrm{n}=1)$. One mass initially benign by core biopsy was resampled 7 months later for new mammographic findings; the repeat core showed FEA, which was also present in the subsequent excision. The remaining 13 core biopsy cases received neoadjuvant therapy: 12 biopsies with IBC and 1 containing friable high grade carcinoma without definitive invasion. After completing neoadjuvant therapy, excision showed pathologic complete response $(n=2)$, residual IBC $(n=9)$, and residual DCIS $(n=1)$. Image-detected metastases at presentation precluded one patient who received neoadjuvant therapy from undergoing surgery. Overall diagnostic concordance for BWH-CB cases was $87.4 \%$. One excision "upgraded" the core biopsy diagnosis of friable DCIS to IBC. Similar to MGH-CB, BWH-CB also showed higher sensitivity but lower specificity than MGH-FNAB (Table 3).

There were no false-negative or false-positive cancer diagnoses with either FNAB or core biopsy in any patient group.

\begin{tabular}{|c|c|c|c|c|}
\hline & $\begin{array}{l}\text { MGH- } \\
\text { FNAB } \\
\text { Observed }\end{array}$ & $\begin{array}{l}\text { BWH-CB } \\
\text { Observed }\end{array}$ & $\begin{array}{l}\text { MGH-CB } \\
\text { Observed }\end{array}$ & $\begin{array}{l}\text { UK NHS } \\
\text { BSP } \\
\text { Minimum } \\
\text { Standard }\end{array}$ \\
\hline $\begin{array}{l}\text { Absolute } \\
\text { sensitivity }\end{array}$ & $66.7 \%$ & $97.3 \%$ & $96.4 \%$ & $>60 \%$ \\
\hline $\begin{array}{l}\text { Complete } \\
\text { sensitivity }\end{array}$ & $91.7 \%$ & $100 \%$ & $100 \%$ & $>80 \%$ \\
\hline Specificity & $65.2 \%$ & $42.86 \%$ & $48 \%$ & $>60 \%$ \\
\hline $\begin{array}{l}\text { PPV of } \\
\text { malignant } \\
\text { biopsy } \\
\text { diagnosis }\end{array}$ & $100 \%$ & $100 \%$ & $100 \%$ & $>95 \%$ \\
\hline $\begin{array}{l}\text { False- } \\
\text { negative } \\
\text { rate }\end{array}$ & $0 \%$ & $0 \%$ & $0 \%$ & $<5 \%$ \\
\hline $\begin{array}{l}\text { False- } \\
\text { positive rate }\end{array}$ & $0 \%$ & $0 \%$ & $0 \%$ & $<1 \%$ \\
\hline $\begin{array}{l}\text { Inadequate } \\
\text { rate }\end{array}$ & $4 \%$ & N/A & N/A & $<25 \%$ \\
\hline $\begin{array}{l}\text { Suspicious } \\
\text { rate }\end{array}$ & $24 \%$ & N/A & N/A & $<20 \%$ \\
\hline
\end{tabular}

Abbreviations: BWH, Brigham and Women's Hospital; $\mathrm{CB}$, core biopsy; FNAB, fine-needle aspiration biopsy; MGH, Massachusetts General Hospital; N/A, not applicable; PPV, positive predictive value; UK NHS BSP, United Kingdom National Health Service Breast Screening Programme.

\section{Wait Times}

MGH-FNAB patients experienced significantly shorter wait times for their first biopsy diagnosis than both core biopsy groups $(P<.0001)$. On average, FNAB diagnoses were available to patients 8 days after clinical presentation. In contrast, $\mathrm{MGH}-\mathrm{CB}$ patients waited 21 days and BWH-CB patients waited 16 days. Thirty-eight MGH-FNAB lesions $(76 \%)$ were biopsied the same day the patient presented for medical care, compared with just 12 (10\%) MGH-CB lesions and 9 (9.5\%) BWH-CB masses. Within 10 days of presentation, 48 (96\%) MGH-FNAB masses were biopsied, compared with 61 (50.4\%) MGH-CB masses, and 60 (63.2\%) BWH-CB masses. For masses that were ultimately benign by excision, MGH-FNAB patients received their first biopsy diagnoses 7 days after presentation on average, compared with 28 days for $\mathrm{MGH}-\mathrm{CB}$ patients and 23 days for BWH-CB patients. MGHFNAB patients with malignant tumors tended to receive their initial biopsy diagnoses sooner than both core biopsy groups: 9 days after presentation, compared with 20 and 15 days for MGH-CB and BWH-CB patients, respectively $(P=.10)$. Pathology 


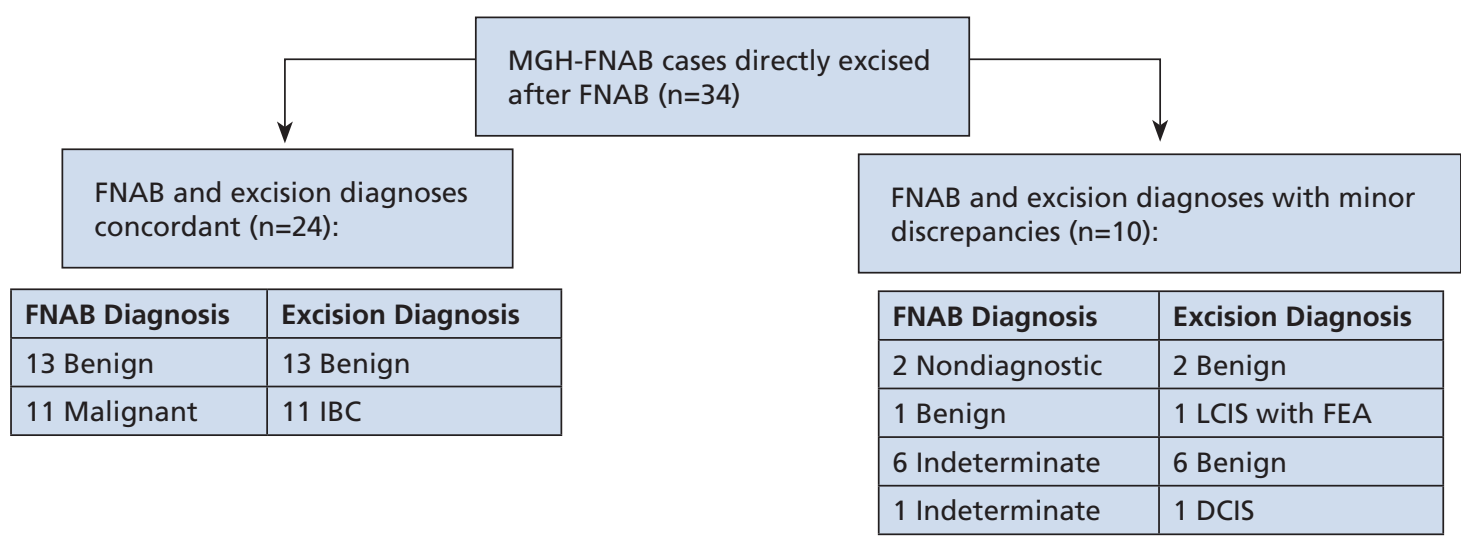

Figure 1. Breast biopsy diagnosis in MGH patients treated with surgical excision after 1 FNAB.

Abbreviations: DCIS, ductal carcinoma in situ; FEA, flat epithelial atypia; FNAB, fine-needle aspiration biopsy; IBC, invasive breast carcinoma; LCIS, lobular carcinoma in situ; MGH, Massachusetts General Hospital.

diagnosis turnaround times were similar for FNAB and core biopsy specimens, averaging 3 to 4 days.

Overall treatment wait times were also similar for all groups: 76 days for MGH-FNAB, 69 days for $\mathrm{MGH}-\mathrm{CB}$, and 63 days for BWH-CB lesions. Within the MGH-FNAB group, patients whose lesions were directly excised $(n=34)$ waited 78 days for treatment, whereas those who underwent repeat biopsy $(\mathrm{n}=16)$ waited 71 days $(P>.5)$. Time to treatment was similar for malignant cases. In cases where biopsy pathology results were indeterminate for malignancy, $\mathrm{MGH}$ FNAB patients tended to receive excision sooner than either core biopsy group: 37 days after presentation compared with 65 days for MGH-CB and 71 days for BWH-CB $(P=.095)$.

\section{Discussion}

Our study of patient wait times and use patterns for diagnosis of palpable breast masses showed that patients referred to pathologists for FNAB received their biopsy procedure and diagnoses 8 to 12 days sooner than patients evaluated by radiologists using image-guided core biopsy $(P<.0001)$. Most patients who underwent FNAB had the biopsy performed the same day of their clinical presentation. A similar statistically significant wait-time difference was observed for the subset with benign breast lesions. Patients with malignant tumors who underwent FNAB tended to receive their biopsy diagnoses sooner than those receiving core biopsy. Surprisingly, wait times for treatment were not significantly different between groups. Notably, undergoing a

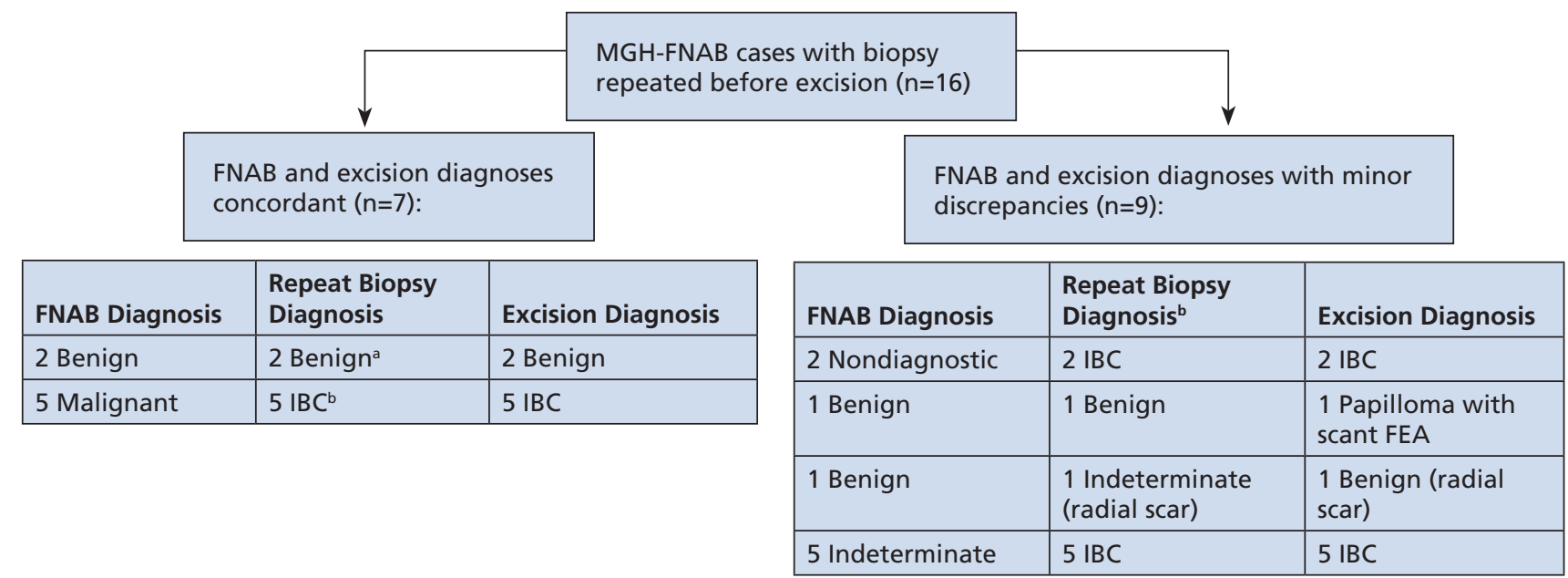

Figure 2. Breast pathology diagnoses in MGH patients receiving more than 1 biopsy before surgical excision.

Abbreviations: FEA, flat epithelial atypia; FNAB, fine-needle aspiration biopsy; IBC, invasive breast carcinoma, MGH, Massachusetts General Hospital. a 1 FNAB, 1 core biopsy.

${ }^{\mathrm{b}}$ All by core biopsy. 
Ly et al

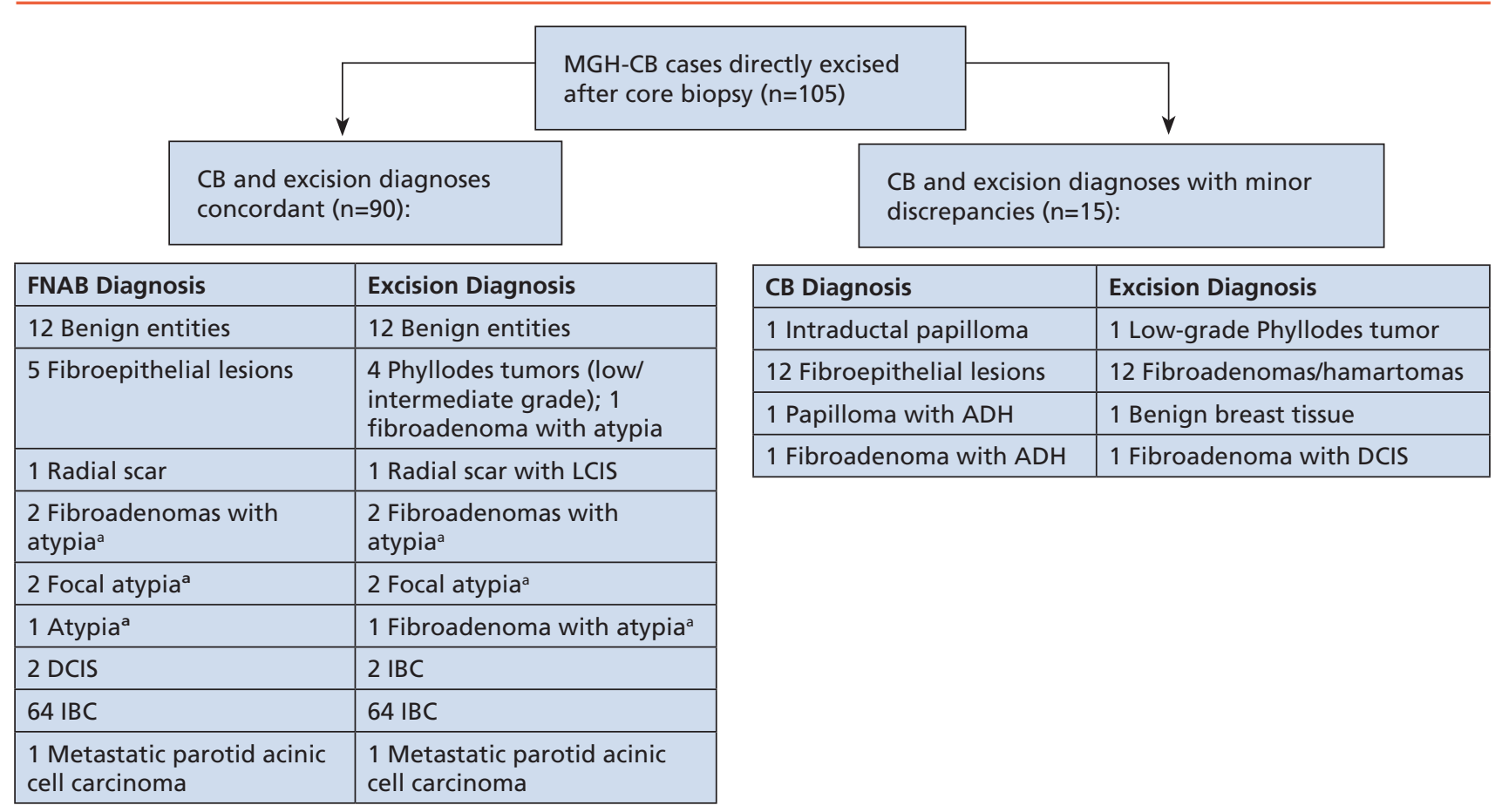

Figure 3. Breast pathology diagnoses in MGH patients treated with surgical excision after core biopsy.

Abbreviations: $\mathrm{ADH}$, atypical ductal hyperplasia; $\mathrm{CB}$, core biopsy; DCIS, ductal carcinoma in situ; IBC, invasive breast carcinoma; LCIS, lobular carcinoma in situ, MGH, Massachusetts General Hospital.

${ }^{a}$ Atypia consists of focal epithelial atypia, flat epithelial atypia, ADH, atypical lobular hyperplasia, or LCIS.

repeat core biopsy after initial breast FNAB did not delay treatment wait times. However, patients who underwent FNAB who had indeterminate biopsy pathology results tended to receive timelier breast mass excision than their core biopsy counterparts in both hospitals.

Our retrospective analysis did not obtain direct feedback from patients regarding their breast care experiences. However, previously published data have demonstrated that waiting for a breast biopsy procedure and pathology results generates significant patient anxiety and stress, and that availability of rapid FNAB diagnoses is able to provide substantial emotional relief to patients. ${ }^{4}$ In our clinical practice, the cytopathologists often follow-up with patients who undergo breast FNAB by telephone 1 to 2 days
BWH-CB cases excised after core biopsy $(n=81)$
$\mathrm{CB}$ and excision diagnoses concordant $(n=70)$ :

\begin{tabular}{|l|l|}
\hline CB Diagnosis & Excision Diagnosis \\
\hline 7 Benign & 7 Benign \\
\hline 4 Indeterminate & $\begin{array}{l}\text { 3 Low-grade Phyllodes tumors; } \\
1 \text { Fibromatosis }\end{array}$ \\
\hline 1 DCIS & 1 IBC \\
\hline 58 IBC & 58 IBC \\
\hline
\end{tabular}

\begin{tabular}{|l|l|}
\hline CB Diagnosis & Excision Diagnosis \\
\hline 3 Benign & $3 \mathrm{ALH} / \mathrm{LCIS}$ \\
\hline $\begin{array}{l}6 \text { Unclassified fibroepithelial } \\
\text { lesions }\end{array}$ & 6 Fibroadenomas \\
\hline 2 Indeterminate & $\begin{array}{l}1 \text { IBC; } 1 \text { DCIS with } \\
\text { papilloma }\end{array}$ \\
\hline
\end{tabular}

Figure 4. Breast pathology diagnoses in BWH patients treated with surgical excision after 1 core biopsy.

Abbreviations: ALH/LCIS, atypical lobular hyperplasia/lobular carcinoma in situ; BGW, Brigham and Women's Hospital; CB, core biopsy; DCIS, ductal carcinoma in situ; IBC, invasive breast carcinoma. 
after their biopsy procedure to inquire about their general condition and address any concerns. Direct quotes from a few of our patients who were informed of their preliminary breast FNAB pathology findings include: "It was comforting to be given preliminary results right on the spot," "I slept a little better last night because I know the results of the biopsy," and "It was wonderful to get my results right away so I didn't have to go home and worry."

During the study period, MGH clinicians appeared to rely equally on core biopsy $(n=305)$ and FNAB $(n=257)$ for palpable breast mass diagnosis. In contrast, image-guided core biopsy was almost exclusively used at BWH, where women were rarely referred for FNAB despite availability of a similar cytopathologist-run FNAB service. Clinician choice of biopsy method did not appear to depend on patient age, social demographics, or cancer history, as these factors were similar in all 3 study groups. Notably, $30 \%$ of palpable breast masses sampled by MGHFNAB were BI-RADS 1 or 2, whereas both core biopsy groups were composed mostly of BI-RADS 4 or 5 lesions $(P<.00001)$. This suggests greater preference for FNAB when clinical and/or radiologic findings supported a benign process. Among core biopsy cases, lesions of low clinical suspicion $(\mathrm{BI}-\mathrm{RADS} \leq 3$ ) were rare in our study; such lesions may have been followed clinically or were not excised subsequent to a core biopsy. Concern for diagnostic discordance in benign biopsies prompted additional tissue sampling at very similar rates in the 3 groups: MGH-FNAB, 44\%; MGH-CB, 46\%; and BWH-CB, 50\%. This suggests an equivalent level of "trust" in FNAB and core biopsy for pathology diagnosis, and that diagnosis by $\mathrm{CB}$ did not reduce the frequency of subsequent breast surgery in this cohort.

Similar to several other previously published studies, we found MGH-FNAB to be highly accurate and comparable to $\mathrm{MGH}-\mathrm{CB}$ and $\mathrm{BWH}-\mathrm{CB}$ for diagnosis. ${ }^{28-38}$ Although core biopsy at both institutions demonstrated greater sensitivity for malignancy, MGH-FNAB was more specific. No false-positive or false-negative diagnoses occurred with either biopsy method. Of the 12 masses categorized as indeterminate by FNAB, 3 were diagnosed as suspicious by FNAB and all contained IBC on excision. The remaining 9 were atypical by FNAB; 3 of these contained carcinoma by excision (2 IBC, 1 DCIS adjacent to a papilloma). With the exception of a mildly elevated suspicious (C4) rate, all UK NHS BSP cytology performance standards were met or exceeded.

In most instances where benign FNAB and core biopsy diagnoses were "upgraded" to indeterminate on excision, the excision showed FEA and ALH/ LCIS, which are both typically non-mass-forming and likely incidental discoveries. In 4 of 6 samples that were initially diagnosed as atypical on FNAB and were benign on follow-up excision, the cytologic preparations showed only mild nuclear atypia involving a few ductal cell groups. Repeat biopsy of malignant FNAB cases was likely performed to confirm the carcinoma to be invasive, for receptor testing, and/or for clinical trial research purposes. All $16(100 \%)$ malignant MGH-FNAB cases contained IBC. This was not surprising because invasive disease is highly probable in the setting of a palpable mass with malignant FNAB diagnosis, approaching 98\% likelihood in one analysis. ${ }^{39}$

Heavy reliance on breast imaging to decide whether biopsy is appropriate should be cautioned against. Once a breast abnormality is detected, biopsy should be performed to avoid diagnostic delay. ${ }^{40}$ An illustrative case from this study involved a 46-year-old woman with BI-RADS 2 "densities, likely cysts," which ultimately proved to be IBC. In addition, there were many BI-RADS 4 lesions sampled by core biopsy that ultimately did not contain malignancy on excision: 29 (49\%) MGH-CB masses and 19 (33\%) BWH-CB masses. These cases underscore the well-known variability of the prevalence of malignancy in the BI-RADS 4 category. ${ }^{41}$ FNAB would be able to exclude carcinoma in many palpable BI-RADS 4 cases. Consequently, FNAB is suitable for any patient with a breast mass. This includes patients with palpable breast lesions of both low and high clinical suspicion for malignancy. FNAB is not suitable for patients with calcifications that are not associated with a mass lesion or any other type of lesion that does not present as a mass. Most indolent breast lesions such as in situ carcinomas, atypical epithelial hyperplasias, and FEA rarely if ever present as mass lesions and would not be referred for FNAB. ${ }^{39}$

The paths to breast biopsy traveled by women are nonuniform and can be convoluted. Our study design eliminated the element of patients seeking care for their breast masses at other hospitals. However, we recognize that even if patients remained at one institution, the timeliness of their breast care 
Ly et al

could still depend on many factors, some of which may be difficult to quantify. These include clinician level of concern for malignancy; availability of physicians qualified to perform breast biopsy procedures; availability of surgeons, operating rooms, and related resources; patient cooperation and availability; patient or physician preference for breast biopsy method; reliance on FNAB rapid diagnoses to triage and expedite management; and the frequent need for multidisciplinary discussions before starting breast cancer treatment. These factors may also influence the breast biopsy type that is chosen for a patient. It is also possible that the timeliness of breast care received by patients would be affected if breast FNAB and $\mathrm{CB}$ were performed by the clinicians who first palpated patients' breast lesions, without having referred patients to another medical specialist. Although this study was not able to draw any definitive conclusions regarding factors that influenced the wait times experienced by patients, we hypothesize that because $76 \%$ of patients who underwent FNAB had the biopsy performed the same day they clinically presented, the availability of FNAB pathologists likely played a significant role in reducing diagnostic wait times. However, it is less clear why treatment wait times were similar between all groups. One possibility is that because many patients who underwent FNAB had breast lesions characterized as BI-RADS 3 or less, there was less clinical urgency for surgical excision.

Breast FNAB has been previously demonstrated to be more cost-effective than breast core biopsy, and our study shows similar results. ${ }^{36,42}$ According to 2015 published Medicare reimbursement rates, palpation-based breast FNAB would cost $\$ 151.24$ (code 10021), which compares very favorably with $\$ 656.53$ for an image-guided breast core biopsy (code 19083). In applying the 2015 figures to this study, the FNAB patient group incurred $\$ 17,561.19$ for all biopsy procedures (34 patients undergoing FNAB only, and 16 undergoing a combination of FNAB and core biopsy). If all 50 FNAB patients had received imageguided core biopsy, the cost would have been $\$ 32,826.50$ for the group. This represents a savings of $\$ 15,265.31$ by using breast palpation-based FNAB first instead of core biopsy, and shows that diagnosis by breast FNAB remains cost-effective even if repeat core biopsy is required in a subset of patients. The cost savings would still be significant $(\$ 12,120.02)$ if cytopathologists had instead performed ultrasoundguided FNAB (codes 10022 and 76942) instead of palpation-based FNAB. Ultrasound-guided FNAB by cytopathologists has been shown to lower nondiagnostic rates and improve diagnostic accuracy and efficiency, and is increasingly becoming part of the cytopathologist's repertoire. ${ }^{43-47}$

The issue of possibly needing a repeat core biopsy is also relevant in the context of patients with breast cancer expected to undergo neoadjuvant chemotherapy. Concern has been raised that FNAB samples may be insufficient for breast cancer biomarker testing, and that core biopsy would still ultimately be required. However, multiple studies have repeatedly shown that FNAB samples provide reliable biomarker information, with high concordance rates $(>90 \%)$ for estrogen receptor (ER), progesterone receptor (PR), and HER2 results when compared with subsequent excision specimens. ${ }^{48-53}$ In addition, the ASCO/College of American Pathologists guideline recommendations accept FNAB as a source of breast cancer biomarker information, further supporting FNAB use for this clinical purpose..$^{54,55}$ In the MGH-FNAB group, 6 of 7 malignant FNAB patient samples tested for ER, PR, and HER2 were entirely concordant with the results derived from the subsequent excisions. Consequently, breast core biopsies would not be absolutely required in neoadjuvant cases if malignant FNAB samples were routinely tested for biomarkers.

To our knowledge, this is the first study to characterize clinical use patterns and evaluate patient wait times with regard to biopsy method for palpable breast mass diagnosis. Based on our findings, breast FNAB performed by experienced pathologists has considerable potential for reducing diagnostic delay without compromising diagnostic accuracy. With its demonstrated cost-effectiveness, reliability for breast cancer receptor testing, safety, and virtual lack of contraindications, FNAB is a powerful and currently underused tool for palpable breast mass diagnosis. ${ }^{26,52,56-62}$ Most palpable breast lesions can be accurately diagnosed by FNAB. Repeat core biopsy would be expected in a subset of patients. However, despite some patients receiving second breast biopsies in our study, their treatment wait times were not longer, and the overall cost-effectiveness of breast FNAB remained unequivocal. More liberal use of breast FNAB and training of FNAB cytopathologists in ultrasound-guided biopsy 
techniques should be encouraged. Teaching radiologists how to perform rapid evaluation of FNAB samples can also be considered.

\section{References}

1. Grady D. Study of breast biopsies finds surgery used too extensively. The New York Times. February 19, 2011:A1.

2. American Cancer Society Estimated new cancer cases by sex and age (years), 2014. Available at: http://www.cancer.org/acs/groups/content/@ research/documents/document/acspc-041776.pdf. Accessed April 3, 2016.

3. Poole K, Hood K, Davis BD, et al. Psychological distress associated with waiting for results of diagnostic investigations for breast disease. Breast 1999;8:334-338.

4. Harcourt D, Rumsey N, Ambler N. Same-day diagnosis of symptomatic breast problems: psychological impact and coping strategies. Psychol Health Med 1999;4:57-71.

5. Thorne SE, Harris SR, Hislop TG, Vestrup JA. The experience of waiting for diagnosis after an abnormal mammogram, Breast J 1999;5:42-51.

6. Flory N, Lang EV. Distress in the radiology waiting room. Radiology 2011;260:166-173.

7. Turner J, Kelly B, Swanson C, et al. Psychosocial impact of newly diagnosed advanced breast cancer. Psychooncology 2005;14:396-407.

8. Jones RV, Greenwood B. Breast cancer: causes of patients' distress identified by qualitative analysis. Br J Gen Pract 1994;44:370-371.

9. Brazda A, Estroff J, Euhus D, et al. Delays in time to treatment and survival impact in breast cancer. Ann Surg Oncol 2010;17(Suppl 3):291-296.

10. Machiavelli M, Leone B, Romero A, et al. Relation between delay and survival in 596 patients with breast cancer. Oncology 1989;46:78-82.

11. Rabinovich $M$, Vallejo $C$, Perez J, et al. Impact of delay to treatment upon survival in 1067 patients with breast-cancer. Int J Oncol 1993;2:197-201.

12. Charlson ME. Delay in the treatment of carcinoma of the breast. Surg Gynecol Obstet 1985;160:393-399.

13. de Melo Gagliato D, Gonzalez-Angulo AM, Lei X, et al. Clinical impact of delaying initiation of adjuvant chemotherapy in patients with breast cancer. J Clin Oncol 2014;32:735-744.

14. Afzelius $P$, Zedeler $K$, Sommer $H$, et al. Patient's and doctor's delay in primary breast cancer. Prognostic implications, Acta Oncol 1994;33:345351.

15. Smith EC, Ziogas A, Anton-Culver H. Delay in surgical treatment and survival after breast cancer diagnosis in young women by race/ethnicity. JAMA Surg 2013;148:516-523.

16. Malin JL, Schneider EC, Epstein AM, et al. Results of the National Initiative for Cancer Care Quality: how can we improve the quality of cancer care in the United States? J Clin Oncol 2006;24:626-634.

17. National Institute for Clinical Excellence. Improving outcomes in breast cancer: manual update. Available at: https://www.nice.org.uk/guidance/ csg1/resources/improving-outcomes-in-breast-cancer-update-773371117. Accessed April 3, 2016.

18. Wilson AR, Marotti L, Bianchi S, et al; and European Society of Breast Cancer Specialists. The requirements of a specialist Breast Centre. Eur J Cancer 1990;49:3579-3587.

19. Perry NM; on behalf of EUSOMA Working Party. Multi-disciplinary aspects of quality assurance in the diagnosis of breast disease. EUSOMA. Available at: http://www.eusoma.org/doc/Multi_disciplinary_aspects of_quality_assurance_in_the_diagnosis_of_breast_disease.pdf. Accessed April 3, 2016.

20. Toomey DP, Cahill RA, Birido N, et al. Rapid assessment breast clinicsevolution through audit. Eur J Cancer 1990;42:2961-2967.

21. Potter S, Govindarajulu S, Shere M, et al. Referral patterns, cancer diagnoses, and waiting times after introduction of two week wait rule for breast cancer: prospective cohort study. BMJ 2007;335:288.

22. Wells KJ, Lee JH, Calcano ER, et al. A cluster randomized trial evaluating the efficacy of patient navigation in improving quality of diagnostic care for patients with breast or colorectal cancer abnormalities. Cancer Epidemiol Biomarkers Prev 2012;21:1664-1672.

23. Lee JH, Fulp W, Wells KJ, et al. Patient navigation and time to diagnostic resolution: results for a cluster randomized trial evaluating the efficacy of patient navigation among patients with breast cancer screening abnormalities, Tampa, FL. PloS One 2013;8:e74542.
24. Psooy BJ, Schreuer D, Borgaonkar J, Caines JS. Patient navigation: improving timeliness in the diagnosis of breast abnormalities. Can Assoc Radiol J 2004;55:145-150.

25. Kumar SK, Gupta N, Rajwanshi A, et al. Immunochemistry for oestrogen receptor, progesterone receptor and HER2 on cell blocks in primary breast carcinoma. Cytopathology 2012;23:181-186.

26. The uniform approach to breast fine-needle aspiration biopsy. NIH Consensus Development Conference. Am J Surg 1997;174:371-385.

27. Singh N, Wells CA. Assessment of accuracy in breast cytology. Cytopathology 2001;12:211-218.

28. Yamaguchi R, Tsuchiya SI, Koshikawa T, et al. Diagnostic accuracy of fineneedle aspiration cytology of the breast in Japan: report from the Working Group on the Accuracy of Breast Fine-Needle Aspiration Cytology of the Japanese Society of Clinical Cytology. Oncol Rep 2012;28:1606-1612.

29. Abdel-Hadi M, Abdel-Hamid GF, Abdel-Razek N, Fawzy RK. Should fine-needle aspiration cytology be the first choice diagnostic modality for assessment of all nonpalpable breast lesions? The experience of a breast cancer screening center in Alexandria, Egypt. Diagn Cytopathol 2010;38:880-889.

30. Simsir A, Rapkiewicz A, Cangiarella J. Current utilization of breast FNA in a cytology practice. Diagn Cytopathol 2009;37:140-142.

31. Farshid G, Rush G. The use of fine-needle aspiration cytology and core biopsy in the assessment of highly suspicious mammographic microcalcifications: analysis of outcome for 182 lesions detected in the setting of a population-based breast cancer screening program. Cancer 2003;99:357-364.

32. Dennison G, Anand R, Makar SH, Pain JA. A prospective study of the use of fine-needle aspiration cytology and core biopsy in the diagnosis of breast cancer. Breast J 2003;9:491-493.

33. Berner A, Davidson B, Sigstad E, Risberg B. Fine-needle aspiration cytology vs. core biopsy in the diagnosis of breast lesions. Diagn Cytopathol 2003;29:344-348.

34. Akçil M, Karaağaoğlu E, Demirhan B. Diagnostic accuracy of fine-needle aspiration cytology of palpable breast masses: an SROC curve with fixed and random effects linear meta-regression models, Diagn Cytopathol 2008;36:303-310.

35. O'Neil S, Castelli M, Gattuso P, et al. Fine-needle aspiration of 697 palpable breast lesions with histopathologic correlation. Surgery 1997;122:824-828.

36. Nagar S, Iacco A, Riggs $T$, et al. An analysis of fine needle aspiration versus core needle biopsy in clinically palpable breast lesions: a report on the predictive values and a cost comparison. Am J Surg 2012;204:193-198.

37. Kurita T, Tsuchiya S, Watarai $\mathrm{Y}$, et al. Roles of fine-needle aspiration and core needle biopsy in the diagnosis of breast cancer. Breast Cancer 2011;19:23-29.

38. Silverman JF, Lannin DR, O'Brien K, Norris HT. The triage role of fine needle aspiration biopsy of palpable breast masses. Diagnostic accuracy and cost-effectiveness. Acta Cytol 1987;31:731-736.

39. Chhieng DC, Fernandez G, Cangiarella JF, et al. Invasive carcinoma in clinically suspicious breast masses diagnosed as adenocarcinoma by fineneedle aspiration. Cancer 2000;90:96-101.

40. Goodson WH and Moore DH. Causes of physician delay in the diagnosis of breast cancer. Arch Intern Med 2002;162:1343-1348.

41. D'Orsi C, Sickles E, Mendelson E, et al. ACR BI-RADS® Atlas, Breast Imaging Reporting and Data System, 5th ed. Reston, VA: American College of Radiology; 2013.

42. Masood S, Rosa M, Kraemer DF, et al. Comparative cost-effectiveness of fine needle aspiration biopsy versus image-guided biopsy, and open surgical biopsy in the evaluation of breast cancer in the era of Affordable Care Act: a changing landscape. Diagn Cytopathol 2015;43:605-612.

43. Dueber J, Pang JC, Lew M, et al. Value of ultrasound guidance in cytopathologist-performed fine-needle aspirations of palpable lesions. J Am Soc Cytopathol 2015;4:195-202.

44. Lieu D. Cytopathologist-performed ultrasound-guided fine-needle aspiration of parathyroid lesions. Diagn Cytopathol 2010;38:327-332.

45. Lieu D. Cytopathologist-performed ultrasound-guided fine-needle aspiration and core-needle biopsy: a prospective study of 500 consecutive cases. Diagn Cytopathol 2008;36:317-324.

46. Abele JS. The case for pathologist ultrasound-guided fine-needle aspiration biopsy. Cancer 2008;114:463-468.

47. Wu M. A comparative study of 200 head and neck FNAs performed by a cytopathologist with versus without ultrasound guidance: evidence for improved diagnostic value with ultrasound guidance. Diagn Cytopathol 2011;39:743-751. 
Ly et al

48. Pegolo E, Machin P, Riosa F, et al. Hormone receptor and human epidermal growth factor receptor 2 status evaluation on ThinPrep specimens from breast carcinoma: correlation with histologic sections determination, Cancer Cytopathol 2012;120:196-205.

49. Domanski AM, Monsef N, Domanski HA, et al. Comparison of the oestrogen and progesterone receptor status in primary breast carcinomas as evaluated by immunohistochemistry and immunocytochemistry: a consecutive series of 267 patients. Cytopathology 2013;24:21-25.

50. Moriki T, Takahashi T, Ueta S, et al. Hormone receptor status and HER2/neu overexpression determined by automated immunostainer on routinely fixed cytologic specimens from breast carcinoma: correlation with histologic sections determinations and diagnostic pitfalls. Diagn Cytopathol 2004;30:251-256.

51. Zoppi JA, Rotundo AV, Sundblad AS. Correlation of immunocytochemical and immunohistochemical determination of estrogen and progesterone receptors in breast cancer. Acta Cytol 2002;46:337-340.

52. Bueno Angela SP, Viero RM, Soares CT. Fine needle aspirate cell blocks are reliable for detection of hormone receptors and HER-2 by immunohistochemistry in breast carcinoma. Cytopathology 2013;24:2632 .

53. Nishimura R, Kagawa A, Tamogami S, et al. Correlation of HER2 gene status assessment by fluorescence in situ hybridization between histological sections and cytological specimens of breast cancer. Breast Cancer 2016;23:211-215

54. Hammond ME, Hayes DF, Dowsett M, et al. American Society of Clinical Oncology/College of American Pathologists guideline recommendations for immunohistochemical testing of estrogen and progesterone receptors in breast cancer (unabridged version). Arch Pathol Lab Med 2010;134:e4872.

55. Wolff AC, Hammond ME, Hicks DG, et al. Recommendations for human epidermal growth factor receptor 2 testing in breast cancer: American Society of Clinical Oncology/College of American Pathologists Clinical Practice Guideline Update. J Clin Oncol 2013;31;3997-4013.

56. Bozzetti C, Nizzoli R, Guazzi A, et al. HER-2/neu amplification detected by fluorescence in situ hybridization in fine needle aspirates from primary breast cancer. Ann Oncol 2002;13:1398-1403.

57. Krishnamurthy S. Applications of molecular techniques to fine-needle aspiration biopsy. Cancer 2007;111:106-122

58. Gong Y, Symmans WF, Krishnamurthy S, et al. Optimal fixation conditions for immunocytochemical analysis of estrogen receptor in cytologic specimens of breast carcinoma. Cancer 2004;102:34-40.

59. Kinsella MD, Birdsong GG, Siddiqui MT, et al. Immunohistochemical detection of estrogen receptor, progesterone receptor and human epidermal growth factor receptor 2 in formalin-fixed breast carcinoma cell block preparations: correlation of results to corresponding tissue block (needle core and excision) samples. Diagn Cytopathol 2013;41:192-198.

60. Löfgren L, Skoog L, von Schoultz E, et al. Hormone receptor status in breast cancer--a comparison between surgical specimens and fine needle aspiration biopsies. Cytopathology 2003;14:136-142.

61. Logan-Young W, Dawson AE, Wilbur DC, et al. The cost-effectiveness of fine-needle aspiration cytology and 14-gauge core needle biopsy compared with open surgical biopsy in the diagnosis of breast carcinoma. Cancer 1998;82:1867-1873.

62. Lannin DR, Silverman JF, Walker C, Pories WJ. Cost-effectiveness of fine needle biopsy of the breast. Ann Surg 1986;203:474-480. 